\title{
Role of complement in in vitro and in vivo lung inflammatory reactions
}

\author{
Boris J. Czermak, ${ }^{\star}{ }^{\dagger}$ Alex B. Lentsch, ${ }^{\dagger}$ Nicolas M. Bless, ${ }^{*}$ Hagen Schmal, ${ }^{*}$ \\ Hans Peter Friedl, ${ }^{*}$ and Peter A. Ward ${ }^{\dagger}$ \\ *D epartment of Trauma Surgery, University of F reiburg, Germany; \\ and ${ }^{\dagger}$ Department of Pathology, University of Michigan M edical School, Ann Arbor
}

\begin{abstract}
Complement is one of the integral buttresses of the inflammatory response. In addition to host defense activities, proinflammatory properties of several complement components are described. This overview elucidates the role of complement in inflammatory reactions in vitro and in vivo, focusing on the complement activation products, $\mathrm{C} 5 \mathrm{a}$, and the membrane attack complex, C5b-9. Using several approaches, the impact of these complement components in mechanisms relevant to neutrophil recruitment is emphasized. In addition, the participation of complement in endothelial superoxide generation and its essential requirement for full expression of lung injury is demonstrated, as are the involved intracellular signal transduction pathways. Understanding the mechanisms of complement-induced proinflammatory effects may provide a basis for future therapeutic blockade of complement and/or its activation products. J. Leukoc. Biol. 64: 40-48; 1998.
\end{abstract}

Key Words: C5a $\cdot$ MAC $\cdot$ CVF $\cdot$ endothelial cells $\cdot$ adhesion molecules · chemokines · rats

\section{INTRODUCTION}

The role of the complement system as an integral part of the host defense response is well known. Functions like facilitation in clearance of circulating immune complexes and their opsonization, platelet aggregation and histamine release induced by anaphylatoxins as well as chemotactic activity of $\mathrm{C} 5 \mathrm{a}$, and the cell lysing capability of distal complement components, which form the membrane attack complex (MAC, C5b-9), have been studied in detail. The essential requirements of complement for clearance of and/or resistance to the biological effects of microorganisms or bacterial endotoxin have been reported for complement components $\mathrm{C} 3, \mathrm{C} 4$, and $\mathrm{C} 6$, demonstrating higher sensitivity to endotoxin in animals deficient in either of these complement factors [1-5]. Also well established but not well understood is the involvement of the complement system in the inflammatory response. Recent data suggest that the involvement of complement in inflammation goes considerably beyond the chemotactic recruitment of neutrophils. As will be emphasized in this review, complement activation products can directly activate phagocytic cells as well as endothelial cells. In this context, two components of the complement cascade, the small activation product, $\mathrm{C} 5 \mathrm{a}$, and the functional unit of the $M A C$, assume prominent roles.

In contrast to the effects of genetically determined deficiencies of the complement components $(C 3, C 4, C 6)$ and associated increased susceptibility to the harmful effects of endotoxin, mice deficient of $\mathrm{C} 5$ have been reported to be less sensitive to the effects of intravenously infused endotoxin than C5-sufficient animals, a finding that appears to be related to lower serum tumor necrosis factor $\alpha$ (TNF- $\alpha)$ levels in the C5-deficient animals [6]. Macrophages obtained from the same C5-deficient mice showed a much reduced TNF- $\alpha$ response in vitro after stimulation with endotoxin. This response has been linked to the availability of the cleavage product $\mathrm{C} 5 \mathrm{a}$, since recombinant $\mathrm{C} 5 \mathrm{a}$ induced a nearly normal in vitro increase of TNF- $\alpha$ responses of macrophages obtained from $\mathrm{C} 5$-deficient mice. These results suggest that $\mathrm{C} 5 \mathrm{a}$ has additional functions that are distinctively different from the chemotactic properties of $\mathrm{C} 5 \mathrm{a}$ generated by the $\mathrm{C} 5$ convertase-induced cleavage of $\mathrm{C} 5$ after activation of the classical or alternative pathways of complement. In other studies the role of $\mathrm{C} 5$ in inflammation has been evaluated by employing an antibody to $\mathrm{C} 5$, preventing generation of both $\mathrm{C} 5 \mathrm{a}$ and the MAC. A significant amelioration of lupus-like autoimmune disease was found in genetically disposed mice as well as a markedly increased survival after $\mathrm{C} 5$ blockade occurred [7]. Similarly, anti-C5 antibody therapy prevented collagen-induced arthritis in mice [8]. Treatment with antibodies to $\mathrm{C} 5$ al so prevented acute cardiac tissue injury and inhibited hyperacute rejection of xenografted organs [9]. It should be emphasized that, in addition to the complementgenerated $\mathrm{C} 5$ convertase, $\mathrm{C} 5$ can be cleaved into chemotactic fragments by serine proteases such as trypsin and by trypsinlike enzymes contained in neutrophil granules [10-12].

\footnotetext{
Abbreviations: MAC, membrane attack complex; TNF- $\alpha$, tumor necrosis factor $\alpha$; SCR 1, soluble complement receptor 1 ; PAGE, polyacrylamide gel electrophoresis; CVF, cobra venom factor; HUVEC, human umbilical vein endothelial cell; PMN, polymorphonuclear leukocytes; IL-8, interleukin-8; MCP-1, monocyte chemoattractant protein-1; NF- $\mathrm{kB}$, nuclear factor- $\mathrm{KB}$; ELISA, enzyme-linked immunosorbent assay; MPO, myeloperoxidase.

Correspondence: Boris J. Czermak, M.D., Department of Pathology, University of Michigan Medical School, Room 7520 MSR B I, 1301 Catherine Road, Ann A rbor, MI 48109-0602. E-mail: czermak@umich.edu

Received January 8, 1998; revised February 19, 1998; accepted February 20, 1998
} 
In addition to activation of platel ets, inducing their aggregation and secretion of serotonin, $\mathrm{C} 5 \mathrm{a}$ is known to induce surface expression of $\mathrm{P}$-selectin on endothelial cells [13]. There is a large body of evidence suggesting a substantial direct and indirect role for $\mathrm{C} 5 \mathrm{a}$ not only in the expression of endothelial adhesion molecules but also for synthesis and release of cytokines from activated macrophages (discussed below in detail). Macrophages can synthesize C5 and may contain enzymes capable of cleaving $\mathrm{C} 5$ to produce $\mathrm{C} 5 \mathrm{a}$. It appears that C5a may serve as an autocrine activator of macrophages through a positive feedback mechanism [B. J. Czermak and P. A. Ward, unpublished observations]. With respect to MAC, the cell-lysing ability of this complex is based on the ring-like structure it forms in cell membranes [reviewed in ref. 14]. After insertion of $\mathrm{C} 5 \mathrm{bC} 6$ complex into cell membranes for which the presence of $\mathrm{C} 7$ is required, $\mathrm{C} 8$ molecules and subsequently $\mathrm{C} 9$ molecules are incorporated into this complex, leading to pore formation in phospholipid membranes. The extent of MACinduced damage as defined by cell lysis has been linked to the number of C9 molecules inserted into this complex. Up to 16 C9 molecules have been described to arrange in these individual ring lesions [15], with at least four C 9 molecules being necessary for each C5b-8 complex to form a lytic lesion through which large intracellular molecules can pass to the exterior of the cell, resulting in cytolysis [16]. In functional immunochemical assays, an average of three to four $\mathrm{C} 9$ molecules have been shown to be bound per C5b-8 complex on MAC-lysed erythrocytes [17]. Although MAC lacking in $C 9$ has some limited biological functions similar to the MAC containing $C 9$, these functions represent only a fraction of those found in the fully formed MAC. Nucleated cells show a higher resistance to lysis by MAC, largely dependent on their metabolic state at any given moment. In addition, the cell membrane content of complement regulatory molecules [such as complement receptor-1, decay accelerating factor (DAF), etc.] affects cell susceptibility to lysis by MAC by regulating the generation of $\mathrm{C} 3$ and $\mathrm{C} 5$ convertases. As will be emphasized below, insertion into endothelial cell membranes of MAC in sublytic concentrations (containing a composition of less than three $C 9$ molecules per C5b-8 complex) results in cell activation events. It should be pointed out that MAC has been detected both as serum SMAC in humans with adult respiratory distress syndrome [18] and in vascular endothelial cells of renal glomeruli in a variety of models of glomerulonephritis [19]. Chemokine release from endothelial cells treated with MAC further adds to the fairly recently recognized proinflammatory role of complement, which has triggered a revival of scientific interest in the complement system.

The current review focuses on functions of the complement activation products, $\mathrm{C} 5 \mathrm{a}$ and $\mathrm{MAC}$, in inflammatory reactions in several in vitro and in vivo models, emphasizing the involvement of complement in crucial steps of acute inflammatory reactions.

\section{STRATEGIES FOR ASSESSMENT OF THE BIOLOGICAL ROLES OF COMPLEMENT}

Assessment of the biological roles of complement can be achieved by a variety of approaches, including the in vitro use of sera deficient in individual complement components, the use of animals that are genetically deficient in complement components (e.g., C3 or C5 in mice, C4 in guinea pigs, C6 in rabbits), or the development of mutant (knockout) mice with specific deficiencies (e.g., involving C3 or the C5a receptor, C5aR). A nother strategy features transgenic expression of products such as DAF in animals, which has for example been emphasized as a way to avoid the hyperacute rejection that occurs in xenografted organs. Finally, complement depletion (with cobra venom factor) and complement blockade [with soluble complement receptor 1 (sCR 1), anti-C5, anti-C5a, etc.] have been used to define biological functions of the complement system. Whereas many of these strategies are able to identify different biological functions related to complement by interrupting the activation of the complement cascade at different stages, they often fail to precisely pinpoint which complement activation products are most importantly associated with a complementdependent inflammatory reaction. For control of the complement system in inflammatory diseases in which complement activation appears advantageous, it seems desirable to leave certain functions (e.g., opsonization or bacterial lysis) largely intact and to interfere with precisely targeted products of the complement system. This can be accomplished by infusion of adequate amounts of SCR 1 to suppress but not absolutely block activation of the complement system, much like the strategy used in immunosuppression. A nother strategy would be aimed at specific blockade of a complement activation product, provided it is clear which activation product is most relevant. Such studies are facilitated by the availability of purified complement components and specific antibodies to single complement activation products. This review focuses on our studies employing complement depletion, blockade of the cleavage product of $\mathrm{C} 5, \mathrm{C} 5 \mathrm{a}$, and exogenous administration of the complement activation product, $\mathrm{C} 5 \mathrm{a}$, as well as in vitro assembly of MAC on cell membranes. As shown below, C $5 b-9$ is a functional unit, as demonstrated by the fact that MAC assembled so as to be devoid of any one of the individual five complement components is largely inactive in either cell lysis or in its pro-inflammatory effects. It should al so be emphasized that single components of $M A C$ are known to be functionally inert as relevant to MAC-dependent responses.

Blockade of $\mathrm{C} 5 \mathrm{a}$ has been made possible by availability of an antibody that is reactive to rat $\mathrm{C} 5 \mathrm{a}$ but not reactive with the parent molecule, $\mathrm{C} 5$. This antibody was raised in rabbits and goats that had been immunized with purified rat C5a. Using immunoprecipitation techniques, $\mathrm{C} 5 \mathrm{a}$ was detected as a band near the $14 \mathrm{kDa}$ marker, as defined in polyacrylamide gel electrophoresis (PAGE). The same band was detected in activated rat serum by Western blot analysis using anti-C $5 \mathrm{a}$, but a band was not detectable in nonactivated serum [20]. A nonspecific control antibody failed to show any evidence of reactivity. The functional properties of the anti-C5a antibody are demonstrated in Figure 1. The serum content of $\mathrm{C} 5 \mathrm{a}$ after systemic complement activation with cobra venom factor (CVF) in rats rose within minutes to a maximal level of nearly 400 $\mathrm{ng} / \mathrm{mL}$ (Fig. 1A). The chemotactic activity present in serum (Fig. 1B) could be completely abolished with anti-C5a, indicat- 
A

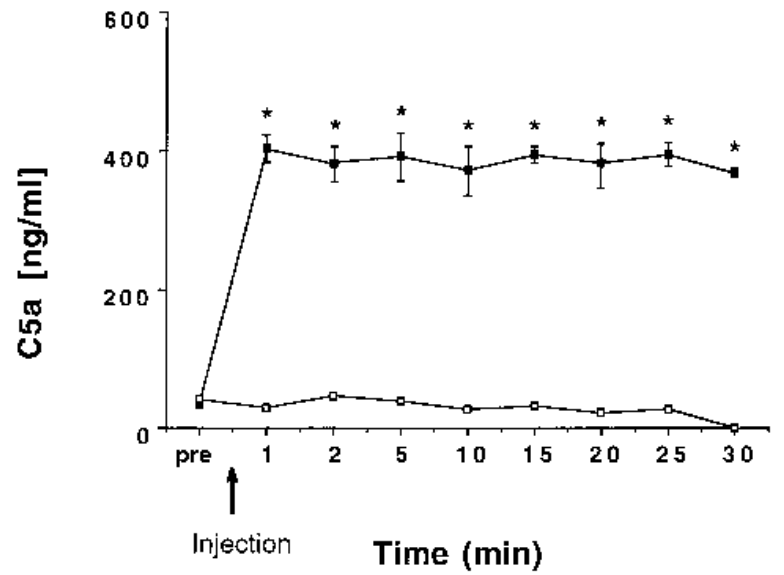

B

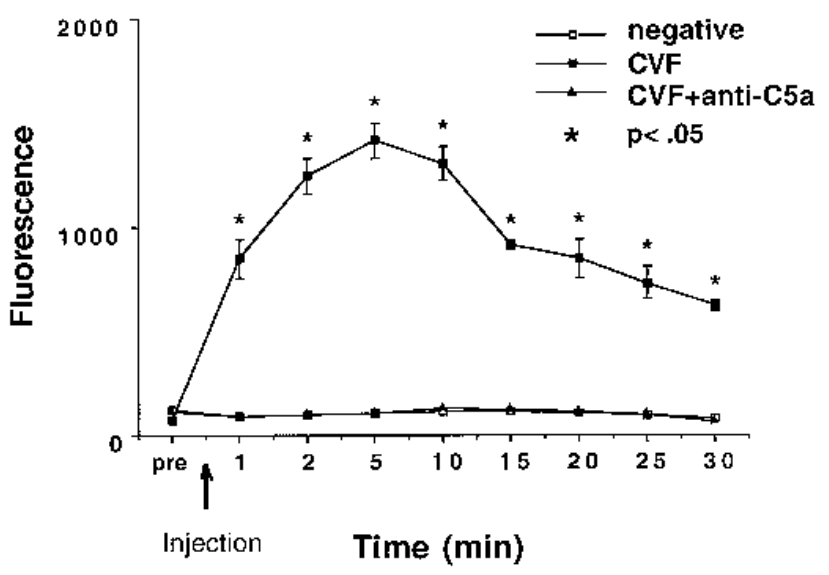

Fig. 1. Serum content of $\mathrm{C} 5 \mathrm{a}(\mathrm{A})$ and chemotactic activity (B) following systemic complement activation by intraperitoneal injection of CVF. Samples were obtained via indwelling arterial catheters. Both antigenic and biological activities in serum could be totally suppressed by in vitro addition of anti-C5a to serum. Statistical comparisons shown are to negative controls (A) and CVF + anti-C5a (B).

ing that all chemotactic activity developing after intravenous infusion of CVF can be assigned to C5a [21].

\section{IN VITRO ENDOTHELIAL EXPRESSION OF P-SELECTIN BY C5a AND MAC}

To study the effects of $\mathrm{C} 5 \mathrm{a}$ on endothelial cells, human umbilical vein endothelial cells (HUVEC) were incubated with increasing doses of human recombinant $\mathrm{C} 5 \mathrm{a}$. It was shown that HUVEC contain mRNA for C5aR and binding studies have indicated a high-affinity $\mathrm{C} 5 \mathrm{aR}$ on HUVEC, although conditions that result in up-regulation of $\mathrm{C} 5 \mathrm{aR}$ have not been identified [13]. Increased expression of P-selectin occurred on HUVEC proportional to the concentration of $\mathrm{C} 5 \mathrm{a}$ used (Fig. 2A). This increased expression went hand-in-hand with enhanced neutrophil (PMN) adhesion to these treated HUVEC (Fig. 2B). A time-course for P-selectin expression in HUVEC stimulated with $250 \mathrm{nM} \mathrm{C5a}$ was demonstrated, occurring within minutes and followed by the return to baseline levels within $30 \mathrm{~min}$. A gain, P-selectin expression and neutrophil adhesion were very closely related, with a peak of $\mathrm{P}$-selectin production at $10 \mathrm{~min}$ and a maximum of neutrophil adherence occurring after $15 \mathrm{~min}$. Similar P-selectin expression has been observed after assembly of sublytic concentrations of the membrane attack complex on HUVEC, with a similar time-course [K. S. Kilgore, unpublished data]. These data are consistent with an earlier report in which the addition of a complement fixing antibody to an epitope on HUVEC in the presence of fresh human serum resulted in P-selectin expression [22]. The role of P-selectin in neutrophil adhesion to C5a-stimulated HUVEC was demonstrated by the use of blocking monoclonal antibodies. A $n$ antibody to P-selectin decreased the binding of neutrophils to C5a-treated HUVEC, whereas blockade by antibody to E-selectin, ICAM-1, or CD18, or a combination thereof, failed to affect neutrophil adhesion (Fig. 3). The inability of antiCD18 and anti-ICAM-1 to affect this adhesion promoting process appears to preclude the role of residual $\mathrm{C} 5$ a present on HUVEC surfaces, resulting in activation of PMN to bring about up-regulation of PMN CD11b/CD18 (Mac-1), which could then engage constitutive ICAM-1 on HUVEC in adhesive interactions.
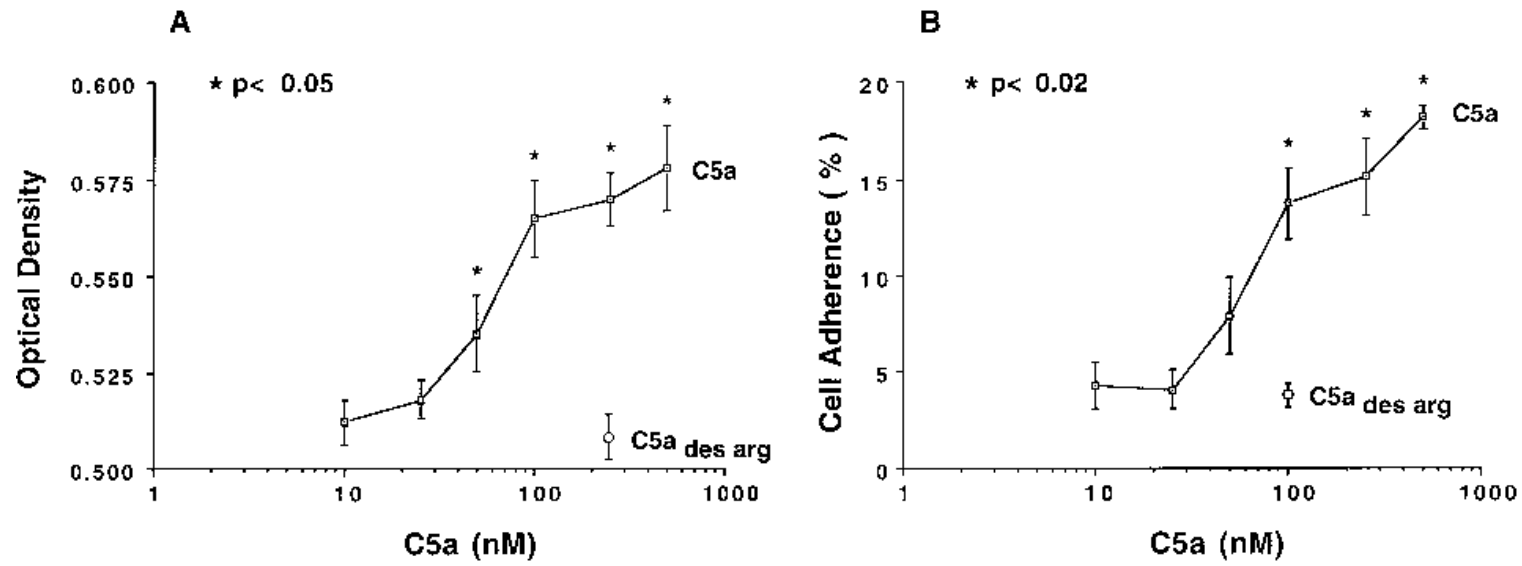

Fig. 2. Dose-response for C5a stimulation of HUVEC. Endothelial P-selectin expression (A) correlated well with biologically functional aspects, both P-selectin expression and PMN adherence (B) being dependent on the dose of $C 5 \mathrm{a}$ administered. 


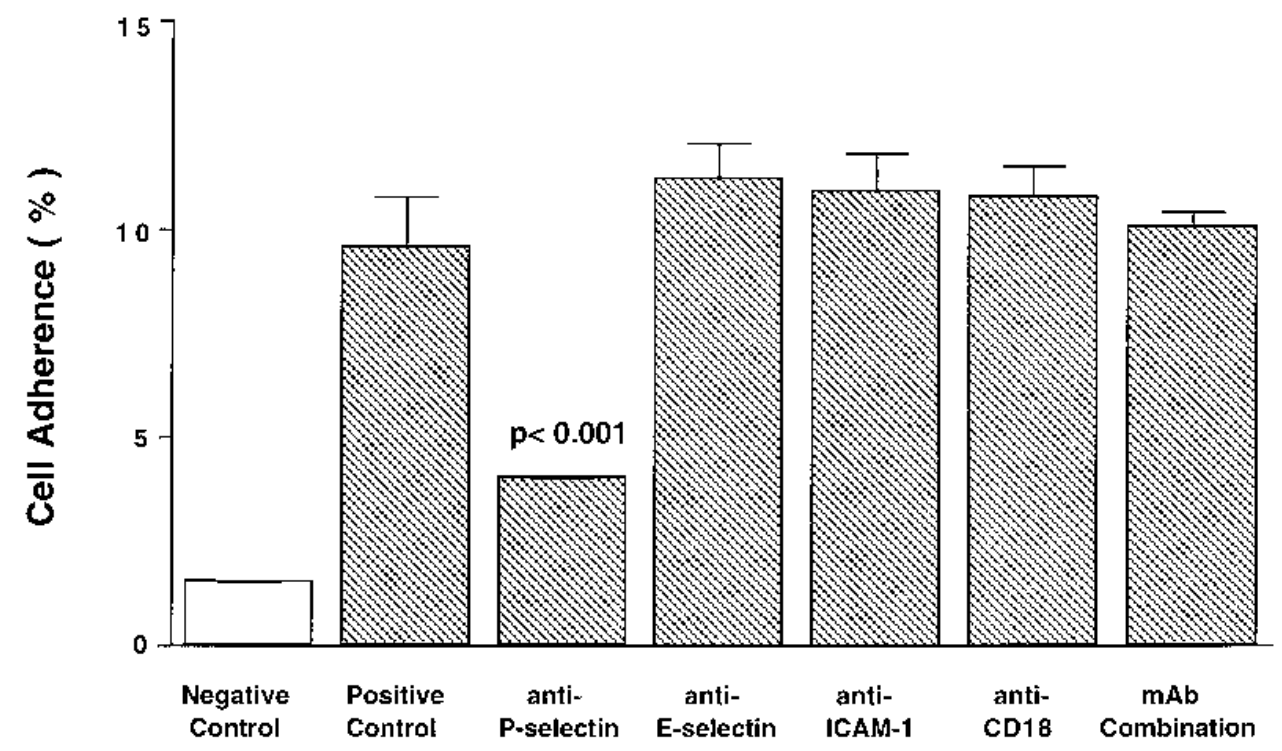

Fig. 3. Neutrophil adhesion to HUVEC stimulated with C5a. Only treatment with an antibody to P-selectin decreased PMN binding to endothelial cells, whereas blockade of E-selectin, ICA M-1, CD18 or combined blockade of these adhesion molecules (mA b combination) was ineffective.

\section{LUNG VASCULAR EXPRESSION OF P-SELECTIN AFTER SYSTEMIC ACTIVATION OF COMPLEMENT}

The ability of complement activation products to participate in the in vivo expression of endothelial P-selectin expression was demonstrated after systemic activation of complement following bolus intravenous infusion of CVF into rats. This type of systemic activation of complement results in acute focal necrosis of lung vascular endothelial cells at points of contact between intravascular PMN and pulmonary capillary endothelial cells. The question arose as to whether circulating neutrophils, which are known to be involved in this injury process, were recruited into lung in a P-selectin-dependent manner. Based on the use of a blocking antibody to P-selectin, it is known that neutrophil accumulation and ensuing lung injury are P-selectin dependent [23]. Using fixation of 125 -anti-Pselectin in order to quantitate lung vascular up-regulation of P-selectin, lung vascular P-selectin was found to be upregulated within minutes after infusion of $C V F$, peaking at 20 min. The use of an irrelevant subclass matched murine antibody (MOPC-21) demonstrated the lack of binding of this control IgG (Fig. 4). The crucial requirement of complement for expression of lung vascular P-selectin was assessed using complement depletion procedures (after repetitive intraperitoneal injections of CVF) or by intravenous treatment with anti-C5a antibody. Both interventions resulted in complete abrogation of up-regulation of lung vascular P-selectin (data not shown), indicating in this experimental model that up-regulation of $\mathrm{P}$-selectin is complement-dependent and, more specifically, C5a-dependent [24].

\section{ENDOTHELIAL ADHESION MOLECULE EXPRESSION INDUCED BY TNF- $\alpha$ AND MAC}

Besides C5a, MAC was found to be capable of modulating adhesion molecule expression on endothelial cells. Stimulation of HUVEC with TNF- $\alpha$ resulted in up-regulation of ICAM-1 and E-selectin [25]. Assembly of sublytic concentrations of MAC alone on HUVEC did not result in significant upregulation of adhesion molecules. However, in the co-presence of low concentrations of TNF- $\alpha$, which produced measurable but limited up-regulation of ICAM-1 and E-selectin, under similar conditions MAC enhanced TNF- $\alpha$-dependent upregulation of ICAM-1 and E-selectin in a synergistic manner (Fig. 5). As would be expected, this increased adhesion molecule expression led to enhanced adhesion of PMN to HUVEC stimulated with TNF- $\alpha$ together with the MAC when compared to stimulation with TNF- $\alpha$ or MAC alone (Fig. 6). Thus, endothelial cells can be stimulated with either $\mathrm{C} 5 \mathrm{a}$ or MAC to bring about direct or indirect up-regulation of endothelial adhesion molecules.

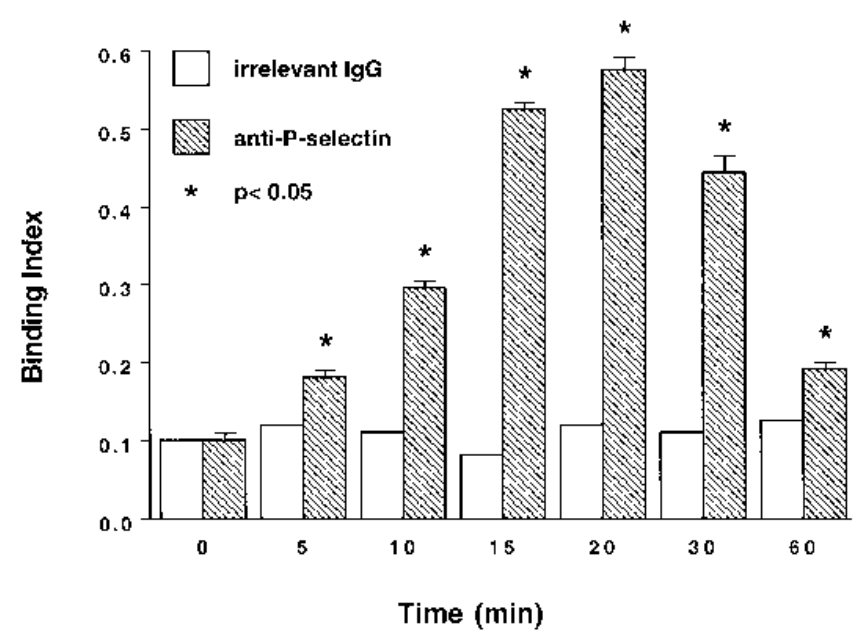

Fig. 4. Time-course of lung vascular P-selectin expression after systemic complement activation as detected by binding of a radiolabeled specific antibody to $\mathrm{P}$-selectin. For the binding index, residual radioactivity in lungs was compared to radioactivity in the blood obtained at the time of death. As a negative control of nonspecific binding, the binding of an irrelevant antibody is depicted. 


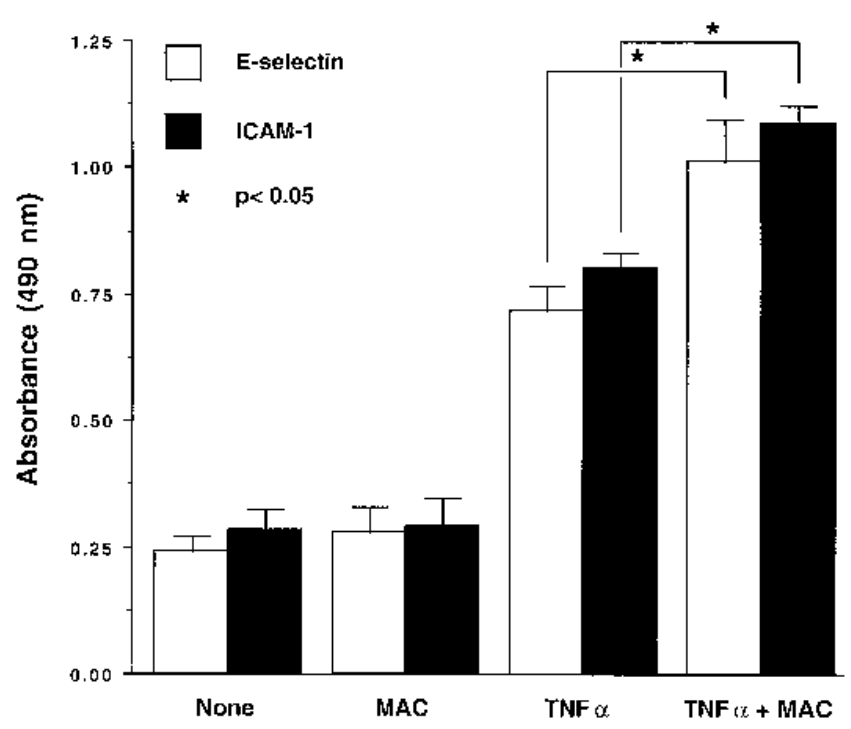

Treatment

Fig. 5. Adhesion molecule expression of stimulated HUVEC monolayers. Stimulation with TNF- $\alpha$ led to an expectable up-regulation of endothelial ICAM-1. Although MAC by itself had no stimulatory effect, the combination of TNF- $\alpha$ and MAC resulted in synergistically increased ICAM-1 expression. Similarly, E-selectin expression, which was inducible by TNF- $\alpha$, was further enhanced in the presence of MAC that, when applied alone, seemed inert.

\section{NF-KB-DEPENDENT INDUCTION OF ENDOTHELIAL INTERLEUKIN-8 (IL-8) AND MONOCYTE CHEMOATTRACTANT PROTEIN-1 (MCP-1) EXPRESSION BY MAC}

Recruitment of neutrophils occurs not only due to engagement of neutrophil counter-receptors with endothelial adhesion molecules but also in response to chemokines, which can be produced by activated endothelial cells and can lead to stimulation of adherent leukocytes. Assembly of sublytic concentrations of MAC on HUVEC resulted in generation of IL-8 and M CP-1 [26], as detected by enzyme-linked immunosorbent assay (ELISA; Fig. 7). The promoter regions of genes

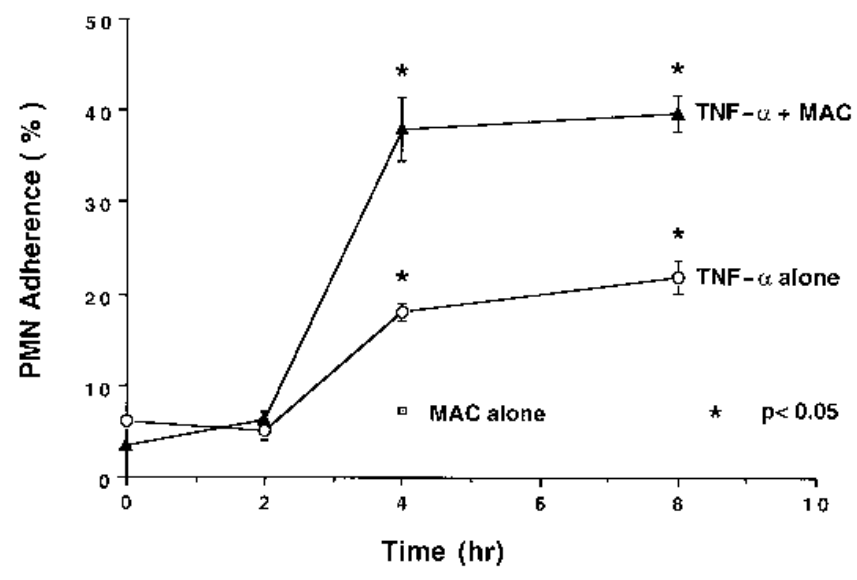

Fig. 6. Neutrophil adhesion to stimulated HUVEC. PMN adhesion caused by stimulation with TNF - $\alpha$ was further increased in the presence of MAC, whereas MAC alone had no stimulatory activity.

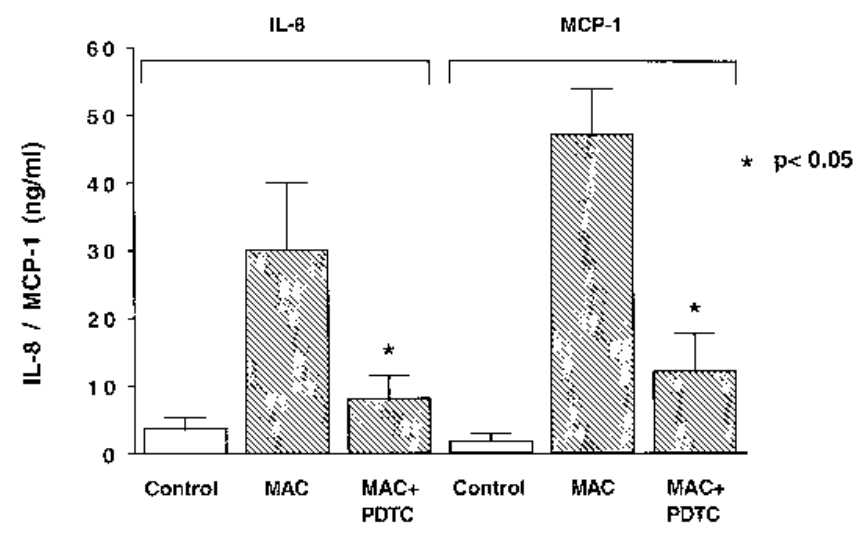

Fig. 7. Chemokine generation by HUVEC stimulated with MAC. The MAC-mediated IL-8 and MCP-1 production was strongly diminished by pretreatment with PTDC, an antioxidant.

responsible for expression of these chemokines are known to be regulated by the family of $\mathrm{NF}-\mathrm{\kappa B}$ transcription factors. Therefore, it was not surprising that assembly of MAC on HUVEC led to chemokine production via NF- $\mathrm{KB}$ activation (translocation to the nucleus). The maximal translocation of NF-KB clearly required intact $M A C$ because the absence of $C 7$ in the formation of MAC abrogated the band shift indicative of the NF- $\mathrm{KB}$ activation. It appears that C5b-8 (MAC-9) is also capable of activating NF- $\mathrm{kB}$ to a limited extent (Fig. 8). As pointed out above, it is known that $\mathrm{C} 5 \mathrm{~b}-8$ has some lytic properties similar to MAC but that this biological activity is quantitatively much less than that of MAC. Thus, reduced activation of NF- $\kappa B$ in HUVEC treated with MAC lacking C 9 is consistent with these earlier observations. In the presence of the antioxidant, pyrrolidine dithiocarbamate, NF- $\mathrm{kB}$ activation was blocked. Under these conditions, greatly reduced chemokine generation (IL-8, MCP-1) by HUVEC was found (see Fig. 7 ), indicating that cytosolic to nuclear translocation of NF- $\mathrm{KB}$ is essential for expression of these chemokines and that production of intracellular oxidants is probably related to activation of $N F-\kappa B$.

\section{ENHANCED ALVEOLAR MACROPHAGE PRODUCTION OF CHEMOKINES BY C5A AND MAC}

Other factors that are directly or indirectly involved in neutrophil recruitment include products from tissue-based macrophages. We investigated in rat alveolar macrophages the extent of chemokine generation (MIP-2 and CINC as members of the CXC chemokine family and MIP-1 $\alpha$ and MCP-1 representing CC chemokines) and the way in which complement activation products might affect this process. C5a or MAC alone caused little or no chemokine generation in vitro by these cells. However, the co-presence of a stimulus such as IgG immune complexes together with either $\mathrm{C} 5 \mathrm{a}$ or $\mathrm{MAC}$ resulted in greatly enhanced production of $C X C$ and $C C$ chemokines [B. ]. Czermak, A. B. Lentsch, N. M. Bless, H. Schmal, H. P. Friedl, and P. A. Ward, unpublished observations]. These data suggest 


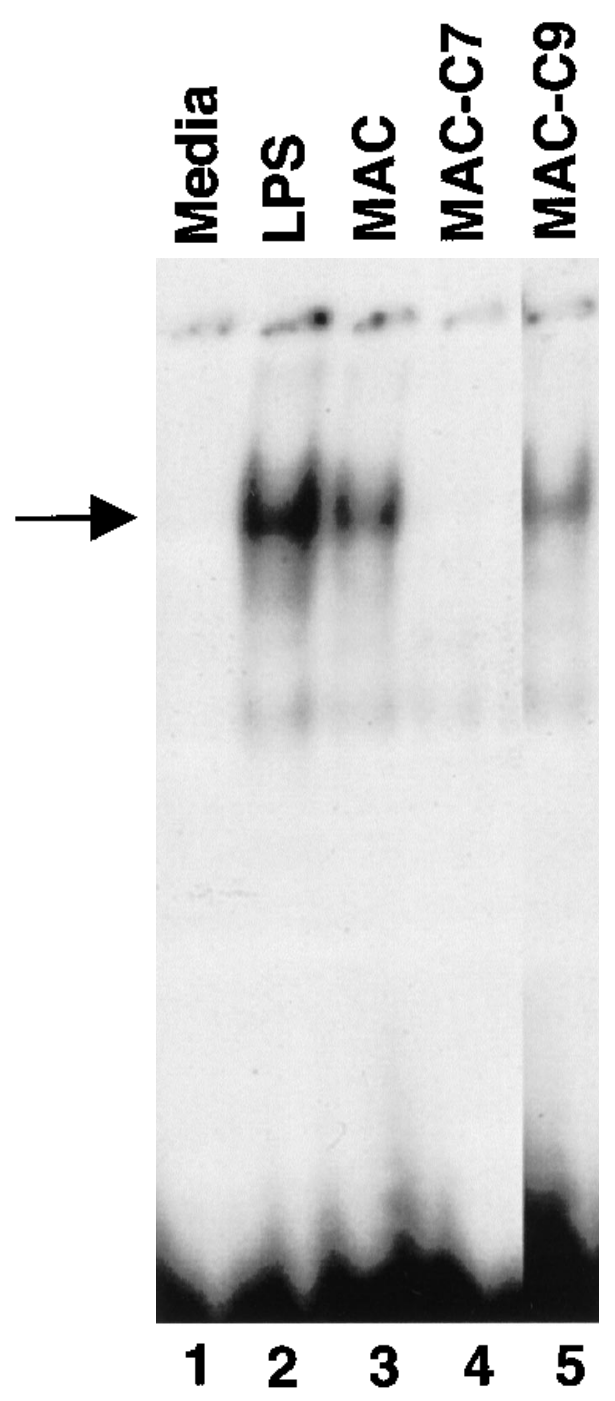

Fig. 8. NF- $\mathrm{KB}$ activation in HUVEC as detected by EMSA analysis. Cells were stimulated with $M A C$ or $M A C$ components in the absence of $C 7$ or $C 9$ or with LPS as a positive control (lane 2). Activation of HUVEC by MAC clearly required insertion into cell membranes because omission of $C 7$ in the assembly of $\mathrm{MAC}$ resulted in no detectable $\mathrm{NF}-\mathrm{KB}$ translocation. In correlation with functional aspects, MAC devoid of $\mathrm{C} 9$ is capable of $\mathrm{NF}-\mathrm{KB}$ activation to some extent, however, to a lesser degree than fully assembled MAC.

that C5a and MAC (in sublytic composition) function synergistically with a stimulus such as IgG immune complexes to enhance chemokine generation in vitro.

\section{INDUCTION OF ENDOTHELIAL SUPEROXIDE PRODUCTION BY C5a}

Endothelial cells have been reported to respond to certain stimuli with the generation of radical oxygen species. C5a (but not $\left(5 \mathrm{a}_{\text {des arg }}\right)$ and TNF- $\alpha$ can each directly induce superoxide production $\left(\mathrm{O}_{2}^{-}\right)$by rat pulmonary artery endothelial cells in a dose-dependent manner [27]. It is interesting to note that the plateau of the $\mathrm{O}_{2}-$ response by $\mathrm{C} 5 \mathrm{a}$-stimulated endothelial cells was virtually identical to that found with neutrophil responses to C5a. TNF $-\alpha$ and C5a agonists work via different intracellular signal transduction pathways. C5a-induced production of $\mathrm{O}_{2}{ }^{-}$ was suppressible in the presence of pertussis toxin (Fig. 9), suggesting a signal transduction pathway involving $G$ proteins. Similar results were found in the presence of staurosporine, suggesting involvement of protein kinase $C$ pathway. The intracellular $\mathrm{Ca}^{2+}$ response to a $\mathrm{C} 5$ a stimulation, as might be predicted based on the known structure of $\mathrm{C} 5 \mathrm{aR}$ (with seven transmembrane-spanning loops), was also abrogated in the presence of pertussis toxin or staurosporine. In contrast, pretreatment of endothelial cells with either pertussis toxin or staurosporine failed to suppress TNF- $\alpha$-induced production of $\mathrm{O}_{2}{ }^{-}$in endothelial cells, confirming that endothelial cell production of $\mathrm{O}_{2}{ }^{-}$caused by either $\mathrm{C} 5 \mathrm{a}$ or TNF $-\alpha$ is running via different signal transduction pathways.

\section{REQUIREMENT OF COMPLEMENT FOR UP-REGULATION OF LUNG VASCULAR ICAM-1 EXPRESSION}

The lung model of injury induced by IgG immune complex deposition in the alveolar space was also evaluated for a complement requirement. In this model the resulting inflammatory reaction is initiated by alveolar macrophages releasing early response cytokines such as TNF- $\alpha$ and interleukin-1 $\beta$ (IL-1 $\beta$ ), which leads via endothelial adhesion molecule expression of ICAM-1 and E-selectin as well as chemokine generation to neutrophil activation and recruitment into lung. Somewhat unexpectedly, complement was found to be required for adhesion molecule expression in the lung vasculature as defined either by complement depletion (with CVF) or by complement blockade (with SCR 1) [28]. Detection of lung vascular ICAM-1 was assessed by binding of labeled antibody to ICAM-1 to the lung vasculature as well as by immunohistological staining for ICAM-1 in lung tissue sections. ICAM-1 was up-regulated in lung injury induced either by IgG immune complex deposition or after intratracheal instillation of TNF- $\alpha$. Treatment with human recombinant SCR-1 decreased ICAM-1 expression by nearly $50 \%$. Complement depletion before lung injury not only

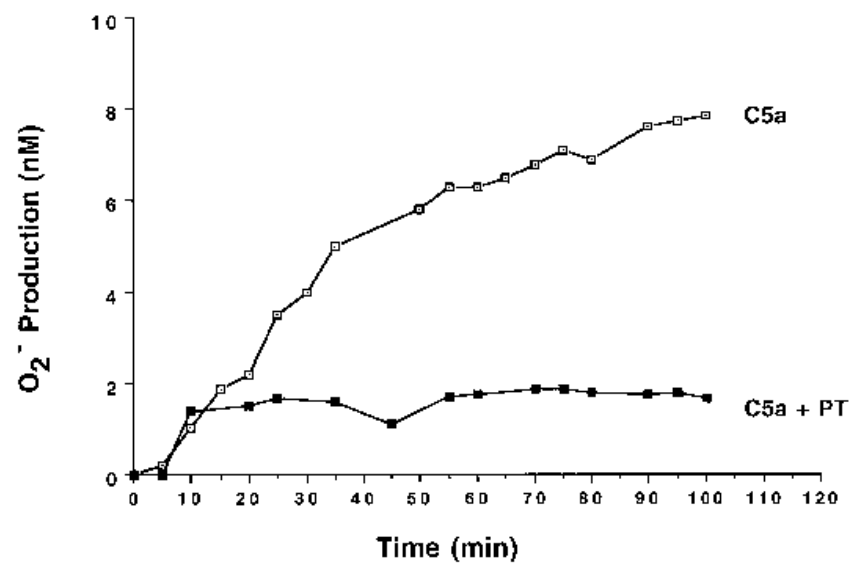

Fig. 9. A brogation of $\mathrm{C} 5$ a-induced endothelial $\mathrm{O}_{2}{ }^{-}$production by pertussis toxin (PT). Pretreatment with pertussis toxin reduces $\mathrm{O}_{2}{ }^{-}$generation to a great extent over a prolonged period of time. 

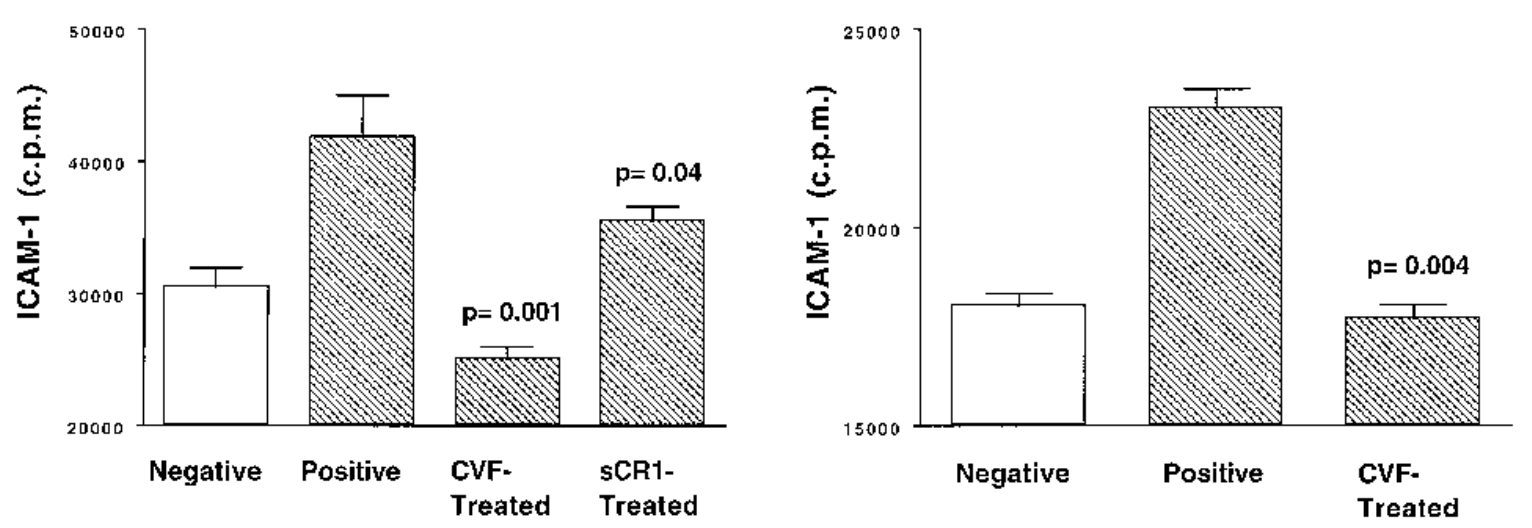

Fig. 10. Lung vascular ICAM-1 up-regulation after alveolar IgG immune complex deposition (A) or intratracheal instillation of TNF- $\alpha$ (B). Complement depletion by repetitive CVF administration not only inhibited ICA M-1 up-regulation but resulted in lower than constitutively expressed ICA M-1 levels in the I gG model of lung injury. Similarly, complement depletion abrogated lung vascular ICAM-1 up-regulation completely in animals undergoing intratracheal treatment with TNF- $\alpha$. Competitive blockade of CR 1 by exogenous administration of SCR 1 decreased IgG immune complex-induced ICAM-1 up-regulation by $50 \%$.

totally suppressed vascular ICAM-1 up-regulation but decreased ICAM-1 levels below that of constitutive expression (Fig. 10A). The suppression of ICAM-1 up-regulation by complement depletion was also seen when the inflammatory reaction was initiated by intratracheal TNF- $\alpha$ instillation (Fig. 10B). Intratracheal blockade of C5a after immune complex deposition al so decreased lung vascular ICAM-1 expression by over $80 \%$ (discussed below, data not shown) [20]. These data clearly point to a linkage between complement and upregulation of lung vascular ICAM-1.

\section{EFFECTS OF ANTI-C5a ON \\ BRONCHOALVEOLAR LAVAGE}

(BAL) TNF- $\alpha$, VASCULAR LEAKAGE, AND LUNG MYELOPEROXIDASE (MPO)

Anti-C5a-induced reduction of lung vascular ICAM-1, the expression of which is known to be TNF- $\alpha$-regulated, was hypothesized to be due to an effect of anti-C5a on levels of TNF- $\alpha$. TNF - $\alpha$ content in BAL fluids was assessed in animals undergoing intrapulmonary deposition of IgG immune complexes. As expected, BAL levels of TNF- $\alpha$ in positive controls were substantially elevated, whereas, in contrast, TNF - $\alpha$ levels of animals receiving anti-C 5 a intratracheally were dramatically reduced (Fig. 11). The treatment with anti-C5a al so reduced in a dose-dependent manner PMN accumulation as well as vascular permeability. As might be expected in this model, the intravenous blockade of $\mathrm{C} 5 \mathrm{a}$ was not significantly protective (Fig. 12). In contrast, intravenous administration of anti-C5a antibody in the CVF model of systemic complement activation was highly effective in reducing neutrophil buildup and increases in lung vascular permeability [20].

\section{CONCLUSION}

Inflammation-enhancing functions of complement activation products are diverse based on information obtained from in vitro and in vivo experiments. Endothelial cells stimulated with either $\mathrm{C} 5 \mathrm{a}$ or MAC react with adhesion molecule expression (P-selectin) and in the presence of an additional stimulus (e.g., TNF $-\alpha$ ) exhibit synergistic expression of $E$-selectin and ICAM-1. Generation of $\mathrm{O}_{2}{ }^{-}$by endothelial cells occurs after stimulation with $\mathrm{C} 5 \mathrm{a}$. MAC can also cause chemokine generation in endothelial cells in a NF-KB-dependent manner. Macrophages react to the co-presence of $\mathrm{C} 5 \mathrm{a}$ or MAC and IgG immune complexes with synergistically increased chemokine production. Complement activation products in in vivo inflammatory reactions can directly stimulate adhesion molecule expression by endothelial cells and early response cytokines and the generation of chemokines, thereby promoting proinflammatory mechanisms at several levels.

Inhibition of the complement system can work as a powerful anti-inflammatory intervention. If control of complement activation is to be achieved by inhibition of a single mediator of the complement cascade, $\mathrm{C} 5$ a seems to be one attractive target. The blockade of $\mathrm{C} 5 \mathrm{a}$, a major player in proinflammatory mechanisms, does not affect other important functions of the complement system such as opsonization and lysis of bacteria. The

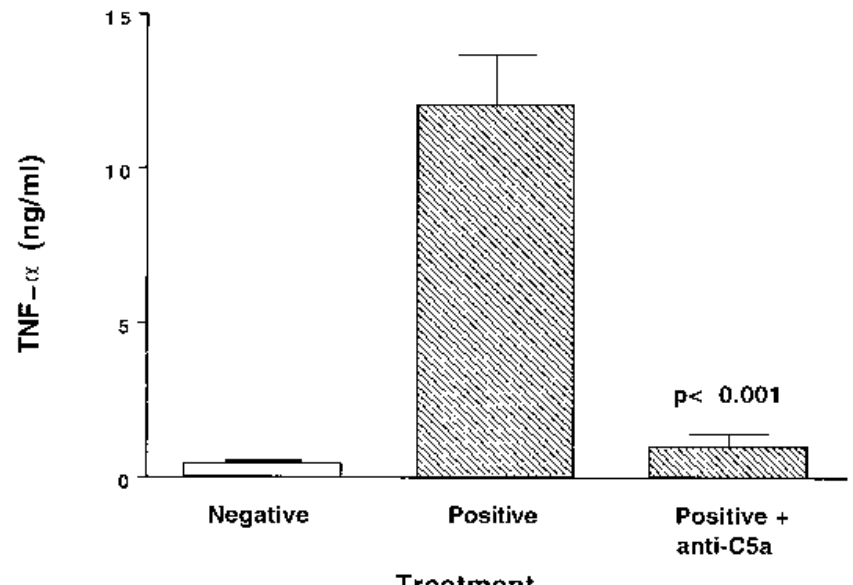

Fig. 11. Bronchoalveolar TNF- $\alpha$ levels after alveolar IgG immune complex deposition. Intratracheal treatment with anti-C5a resulted in TNF- $\alpha$ levels that were indistinguishable from negative control values. 
A

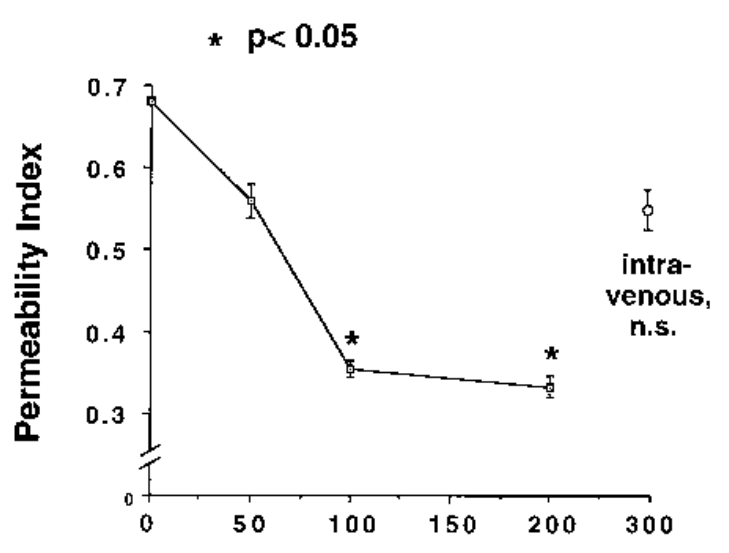

B

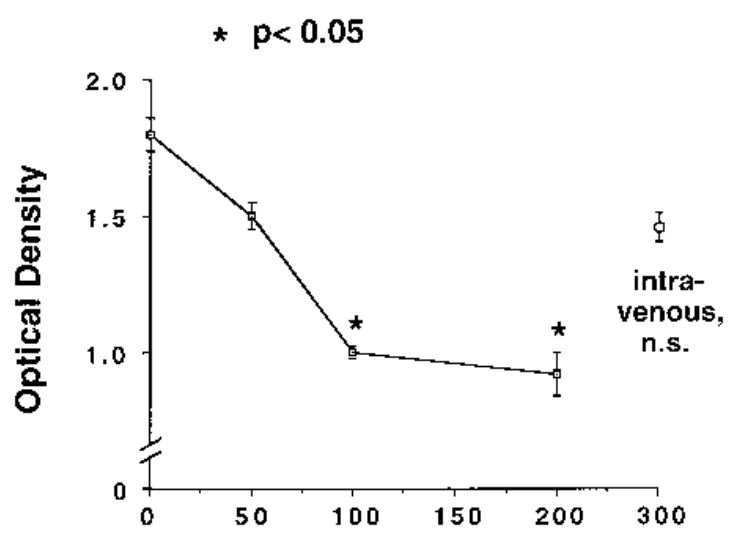

Intratracheal Treatment with anti-c5a $(\mu \mathrm{g})$

Fig. 12. Lung injury parameters after alveolar IgG immune complex deposition. The permeability index (A) as a measure of vascular leakage and MPO contents of lung extracts (B) indicating PMN accumulation decreased significantly after intratracheal treatment with anti-C5a in a dose-dependent manner.

distinct anti-inflammatory effects of complement blockade or inhibition are very much dependent on choosing the right time frame and the appropriate conditions for intervention. It will be essential to have such information if there are to be useful clinical applications of complement inhibition. The presented data point to complex and diverse pathways leading to inflammatory responses that depend directly or indirectly on complement activation products. This suggests that inhibition or blockade of complement and/or its activation products may be useful in the treatment of human inflammatory conditions.

\section{REFERENCES}

1. Quezado, Z. M., H offman, W. D., Winkelstein, J. A., Yatsiv, I., K oev, C. A., Cork, L. C., Elin, R. J., Eichacker, P. Q., Natanson, C. (1994) The third component of complement protects against Escherichia coli endotoxininduced shock and multiple organ failure. J. Exp. Med. 179, 569-578.

2. Fischer, M. B., Prodeus, A. P., Nicholson-Weller, A., Ma, M., Murrow, J., Reid, R. R., Warren, H. B., Lage, A. L., Moore, F. D., Rosen, F. S., Carroll, M. C. (1997) Increased susceptibility to endotoxin shock in complement C3- and C4-deficient mice is corrected by C1 inhibitor replacement. J. Immunol. 159, 976-982.

3. May, J. E., Kane, M. A ., Frank, M. M. (1972) H ost defense against bacterial endotoxemia - contribution of the early and late components of complement to detoxification. J. Immunol. 109, 893-895.

4. Wessels, M. R., Butko, P., Ma, M., Warren, H. B., Lage, A. L., Carroll, M. C. (1995) Studies of group B streptococcal infection in mice deficient in complement component $\mathrm{C} 3$ or $\mathrm{C} 4$ demonstrate an essential role for complement in both innate and acquired immunity. Proc. Natl. Acad. Sci. USA 92, 11490-11494.

5. Johnson, K. J., Ward, P. A. (1971) Protective function of C6 in rabbits treated with bacterial endotoxin. J. Immunol. 106, 1125-1127.

6. Barton, P. A., Warren, J. S. (1993) Complement component C5 modulates the systemic tumor necrosis factor response in murine endotoxic shock. Infect. Immun. 61, 1474-1481.

7. Wang, Y., Hu, Q., Madri, J. A., Rollins, S. A., Chodera, A., Matis, L. A. (1996) A melioration of lupus-like autoimmune disease in NZB/W F 1 mice after treatment with a blocking monoclonal antibody specific for complement component C5. Proc. Natl. Acad. Sci. USA 93, 8563-8568.

8. Wang, Y., Rollins, S. A., Madri, J. A., Matis, L. A. (1995) Anti-C5 monoclonal antibody therapy prevents collagen-induced arthritis and ameliorates established disease. Proc. Natl. Acad. Sci. USA 92, 89558959.
9. Kroshus, T. J., Rollins, S. A., Dalmasso, A. P., Elliott, E. A., Matis, L. A., Squinto, S. P., Bolman, R. M., 3rd (1995) Complement inhibition with an anti-C5 monoclonal antibody prevents acute cardiac tissue injury in an ex vivo model of pig-to-human xenotransplantation. Transplant. 60, 11941202.

10. Ward, P. A., Zwaivler, N. J. (1973) Quantitative phagocytosis by neutrophils. II. R elease of the C5-cleaving enzyme and inhibition of phagocytosis by rheumatoid factor. I. Immunol. 111, 1777-1782.

11. Hill, J. H., Ward, P. A. (1969) C3 leukotactic factors produced by a tissue protease. J. Exp. Med. 130, 505-518.

12. Ward, P. A., Chapitis, J., Conroy, M. C., Lepow, I. H . (1973) Generation by bacterial proteinases of leukotactic factors from human serum and $\mathrm{C} 3$ and C5. J. Immunol. 110, 1003-1009.

13. Foreman, K. E., Vaporciyan, A. A., B onish, B. K., Jones, M. L., J ohnson, K. J., Glovsky, M. M., Eddy, S. M., Ward, P. A. (1994) C5a-induced expression of P-selectin in endothelial cells. J. Clin. Invest. 94, 1147-1155.

14. Morgan, B. P. (1989) Complement membrane attack on nucleated cells: resistance, recovery and non-lethal effects. Biochem. J. 264, 1-14.

15. Podack, E. R. (1988) Cytolytic Lymphocytes and Complement. (E. R. Podack, ed.) Boca Raton, FL: CR C Press, 173-184.

16. Ramm, L. E., Whitlow, M. B., Mayer, M. M. (1985) The relationship between channel size and number of $\mathrm{C} 9$ molecules in the C $5 \mathrm{~b}-9$ complex. J. Immunol. 134, 2594-2599.

17. Stewart, J. L., Monahan, J. B., Brickner, A., Sodetz, J. M. (1984) Measurement of the ratio of the eight and ninth components of human complement on complement-lysed membranes. Biochemistry 23, 40164022.

18. Langlois, P. F., Gawryl, M. S. (1988) Accentuated formation of the terminal C5b-9 complement complex in patient plasma precedes development of the adult respiratory distress syndrome. Am. Rev. Respir. Dis. 138, 368-375.

19. Perkinson, D. T., Baker, P. J ., Couser, W. G., J ohnson, R. J ., A dler, S. (1985) Membrane attack complex deposition in experimental glomerular injury. Am. J. Pathol. 120, 121-128.

20. Mulligan, M. S., Schmid, E., Beck-Schimmer, B., Till, G. O., Friedl, H. P., Brauer, R. B., Hugli, T. E., Miyasaka, M., Warner, R. L., Johnson, K. J., Ward, P. A . (1996) R equirement and role of C5a in acute lung inflammatory injury in rats. J. Clin. Invest. 98, 503-512.

21. Schmid, E., Warner, R. L., Crouch, L. D., Friedl, H. P., Till, G. O., Hugli, T. E., Ward, P. A . (1997) Neutrophil chemotactic activity and C5a following systemic activation of complement in rats. Inflammation 21, 325-333.

22. H attori, R., H amilton, K. K., M CE ver, R. P., Sims, P. J. (1989) Complement proteins $C 5 b-9$ induce secretion of high molecular weight multimers of endothelial von Willebrand factor and translocation of granule membrane protein GM P-140 to the cell surface. J. Biol. Chem. 264, 9053-9060.

23. Mulligan, M. S., Polley, M. J., Bayer, R. J., Nunn, M. F., Paulson, J. C., Ward, P. A. (1992) Neutrophil-dependent acute lung injury, requirement for P-selectin (GM P-140). J. Clin. Invest. 90, 1600-1607. 
24. Mulligan, M. S., Schmid, E., Till, G. O., Hugli, T. E., Friedl, H. P., R oth, R. A., Ward, P. A. (1997) C5a-dependent upregulation in vivo of lung vascular P-selectin. J. Immunol. 158, 1857-1861.

25. Kilgore, K. S., Shen, J. P., Miller, B. F., Ward, P. A., Warren, J. S. (1995) Enhancement by the complement membrane attack complex of TNF $\alpha$ induced endothelial cell expression of E-selectin and ICAM-1. I. Immunol. 155, 1434-1441.

26. Kilgore, K. S., Schmid, E., Shanley, T. P., Flory, C. M., Maheswari, V., Tramontini, N. L., Cohen, H., Ward, P. A ., Friedl, H. P., Warren, J. S. (1997) Sublytic concentrations of the membrane attack complex (MAC) of complement induce endothelial interleukin 8 (IL-8) and monocyte protein 1 (MCP-1) through nuclear factor- $\kappa B$ activation. Am. J. Pathol. 150, 2019-2031.

27. Murphy, H. S., Shayman, J. A., Till, G. O., Maroughui, M., Owens, C. B., Ryan, U. S., Ward, P. A. (1992) Superoxide responses of endothelial cells to $\mathrm{C} 5 \mathrm{a}$ and TNF $\alpha$ : divergent signal transduction pathways. Am. J. Physiol. 263, L51-L59.

28. Vaporciyan, A. A., Mulligan, M. S., Warren, J. S., Barton, P. A., Miyasaka, M., Ward, P. A. (1995) Up-regulation of lung vascular ICAM-1 in rats is complement dependent. J. Immunol. 155, 1442-1449. 